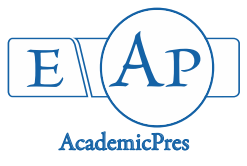

Doğru A (2020)

Notulae Scientia Biologicae 12(4):829-835

DOI: $10.15835 / 12410815$

Research Article

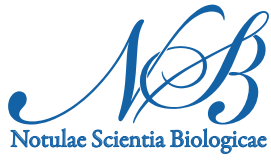

\title{
Photochemical responses of cucumber (Cucumis sativus L.) plants to heat stress
}

\author{
Ali DOĞRU \\ Sakarya University Faculty of Arts and Science Department of Biology Esentepe 54187 Sakarya, \\ Turkey; adogru@sakarya.edu.tr
}

\begin{abstract}
In this study, photochemical responses of cucumber (Cucumis sativus L.) cultivar, 'Beith Alpha F1', under moderate and severe heat stress $\left(45^{\circ} \mathrm{C}\right.$ and $55^{\circ} \mathrm{C}, 4$ hours) was studied. Chlorophyll a fluorescence measurement and the results of the JIP test indicated that severe heat stress was more drastically affected the photosynthetic activity as compared to moderate heat stress in the cotyledons of cucumber plants. Severe heat stress, for example, led to the increased level of Fo and decreased level of $\mathrm{Fm}, \mathrm{Fv} / \mathrm{Fo}$, and $\mathrm{Fv} / \mathrm{Fm}$, suggesting remarkable photoinhibition on electron transport reactions in cucumber plants. Also, severe heat stress caused the increased level of accumulation of inactive reaction centers, resulting in a decreased amount of trapped light energy and electron transport on PSII. The enhanced values of DIo/RC and $\phi_{\mathrm{Do}}$ in the cotyledons of cucumber plants indicated that the trapped energy cannot be used for photochemical reactions and lost as heat. Consequently, the reduction of the plastoquinone pool was partly inhibited due to the decreased yield of photochemistry. As a result, it may be concluded that severe heat stress inhibited PSII activity in several points and decreased photosynthetic yield in the cotyledons of cucumber plants.
\end{abstract}

Keywords: chlorophyll a fluorescence; cucumber; Cucumis sativus; heat stress; JIP test

\section{Introduction}

Rising temperature due to climate change poses a serious threat to agricultural yields worldwide (Wang et al., 2018). It has been estimated that the temperature will increase by $0.2^{\circ} \mathrm{C}$ every ten years until the year 2100 (Sehgal et al., 2016). Heat stress is generally defined as prevailing temperature conditions above a certain threshold value for a period sufficient to cause irreversible damage to plant growth and development (Wahid et al., 2007). The growing need for food and agricultural yield losses due to global warming show that food security needs to be improved urgently (Abdelrahman et al., 2017). For this reason, it is very important to investigate the physiological, biochemical, and molecular responses of plants against heat stress.

The effect of heat stress on plant metabolism varies depending on the temperature, the exposure time, and the rate of increase in temperature (Wahid et al., 2007). Due to the disruption of the cellular organization at extremely high temperatures, significant metabolic damages and even cell death may occur in a short period (Schöffl et al., 1999). At lower temperatures, the exposure time of the plant must be longer for cellular damage or death to occur. The direct effects of heat stress on plants include protein denaturation and aggregation, 
inhibition of protein synthesis and enzyme activity, increased membrane fluidity, and disruption of membrane integrity. These damages result in inhibition of photosynthesis and growth, the formation of various toxic compounds, and active oxygen species (Schöffl et al., 1999).

Photosynthesis is the most important process that enables the conversion of light energy to biological energy in plants. The temperatures $10-15^{\circ} \mathrm{C}$ above the value considered optimum for plant growth and development generally cause heat stress and cause a reduction in photosynthetic activity (Allakhverdiev et al., 2008). It has been well known that photosynthesis is highly sensitive to heat stress. This is mainly due to structural deformations in thylakoid membranes and consequently inhibition of redox reactions in chloroplasts (Biswal et al., 2011). Chen et al. (2017) reported that chloroplasts are organelles that enable cellular signalling events to be activated against heat stress. Both abiotic and biotic stress factors that reduce photosynthetic activity also reduce the growth rate of plants. Therefore, it is essential to examine the changes in photosynthetic activity in plants under stress. Today, chlorophyll a fluorescence has been reported to be the most modern and reliable technique for measuring photosynthetic activity (Maxwell and Johnson, 2000; Doğru, 2019; Doğru and Çakırlar, 2020a, b). The basic principle of chlorophyll a fluorescence kinetics is the redox state of quinone $A\left(Q_{A}\right)$, which is the primary electron acceptor of photosystem II (PSII). Accordingly, the fluorescence yield is low when the $\mathrm{Q}_{\mathrm{A}}$ is in the oxidized state, and the fluorescence yield is high when it is reduced. In this case, fluorescence yield is directly related to the net concentration of $\mathrm{Q}_{\mathrm{A}^{-}}$(Govindjee, 2004). Also, at the minimum fluorescence ( $\mathrm{Fo}$ ), that is, at the "O" point, all $\mathrm{Q}_{\mathrm{A}}$ molecules are in an oxidized state, the reaction centers of PSII are open, and primary photochemical processes are at maximum level. However, at the maximum fluorescence $(\mathrm{Fm})$, that is, at the "P" point, all $\mathrm{Q}_{\mathrm{A}}$ molecules are reduced, the reaction centers of PSII are closed and primary photochemical processes are at a minimum level (Govindjee, 2004). If the chlorophyll a fluorescence signals are plotted versus the logarithm of time, the "OJIP" curve is obtained. The basic principle of the OJIP curve can be explained as follows: When light is applied to the surface of a leaf adapted to the dark, the fluorescence of chlorophyll $a$ increases from the minimum level ("O") to the "J" level $\left(\mathrm{Fj}_{\mathrm{j}}\right)$ within $2 \mathrm{~ms}$ due to reduction of $\mathrm{Q}_{\mathrm{A}}$ molecules. It then rises to the "I" point $\left(\mathrm{F}_{1}\right)$ in about $30 \mathrm{~ms}$ due to the reduction of the entire plastoquinone pool. In the last stage, chlorophyll a fluorescence increases form the "I" point to the maximum level ("P" or Fm) due to the higher electron density in the acceptor side of photosystem I (PSI) (Govindjee, 2004). The technique that enables chlorophyll a fluorescence signals to examine the changes exhibited at "J", "I", and "P" points of the OJIP curve and the interactions between these changes is called the JIP test (Strasser et al., 2004). JIP test is used in the field of plant biology and agriculture to understand the reactions of the photosynthetic apparatus under many different environmental conditions (Yusuf et al., 2010). JIP test is based on energy flow theories in thylakoid membranes (Force et al., 2003). This test allows the investigation of the energy flow entering and leaving the PSII through parameters (Table 1) directly measured and calculated with the help of some equations.

Accordingly, this study aims to examine the physiological changes caused by the moderate and severe heat stress in cucumber plants by chlorophyll a fluorescence technique and JIP test.

\section{Materials and Methods}

\section{Plant material, growth conditions, and experimental design}

In this study, a cucumber (Cucumis sativus L.) genotype, 'Beith Alpha F1', was used. The seeds were first surface-sterilized with $5 \%$ sodium hypochlorite solution for $30 \mathrm{~min}$. Then they were washed three times and imbibed in distilled water for $24 \mathrm{~h}$. After imbibition, seeds were sown in plastic pots containing perlite and watered with half-strength Hoagland solution. Plants were grown in a growth chamber at $27 / 22^{\circ} \mathrm{C}$ day/night temperature, 16 -h photoperiod, the irradiance of $200 \mu \mathrm{mol} \mathrm{m} \mathrm{s}^{-1}$, and $40-45 \%$ relative humidity. On the $10^{\text {th }}$ day of growth, moderate $\left(45^{\circ} \mathrm{C}\right)$ and severe $\left(55^{\circ} \mathrm{C}\right)$ heat stress and treatment were applied to seedlings for 4 
hours, which was determined based on the previous studies. After 24 hours of heat stress application, chlorophyll a fluorescence measurement was done on the intact plants.

Table 1. Identification of some chlorophyll a fluorescence and JIP test parameters (Kalaji et al., 2011)

\begin{tabular}{|c|c|}
\hline Parameters & \\
\hline$F_{O}$ & Chlorophyll a fluorescence intensity measured when all PSII reaction centers are assumed to be open \\
\hline$F_{m}$ & Maximum chlorophyll a fluorescence intensity measured when all PSII reaction centers are closed \\
\hline$F_{V}$ & Variable chlorophyll a fluorescence (Fm-Fo) \\
\hline$F_{V} / F_{m}$ & Maximum quantum efficiency of PSII \\
\hline$F_{V} / F_{O}$ & A value that is proportional to the activity of the water-splitting complex on the donor side of PSII (the \\
efficiency of Hill reaction or photolysis
\end{tabular}

\section{Chlorophyll a fluorescence measurement}

Chlorophyll a fluorescence measurement was done by plant efficiency analyser (Handy PEA fluorimeter, Hansatech Instruments Ltd., Pentney, Kings Lynn, Norfolk, England). Cucumber seedlings were pre-darkened for 45-60 $\mathrm{min}$ at room temperature. Chlorophyll a fluorescence induction transient was measured on the cotyledons when they were exposed to a strong light pulse $\left(3500 \mu \mathrm{mol}\right.$ photons $\left.\mathrm{m}^{-2} \mathrm{~s}^{-1}\right)$. The data were analysed and the JIP test was conducted using Biolyzer software (Strasser et al., 2000). Measurements of chlorophyll a fluorescence were done on 10 plants from each treatment and using 3 replicates for each plant $(n=30)$.

\section{Statistical analysis}

Experiments were a randomized complete block design with three independent replicates. Analysis of variance (ANOVA) was performed using SPSS 20.0 statistical software for Windows. To separate significant differences between means, Duncan (least significant difference) test was used at $\mathrm{P} \leq 0.05$.

\section{Results and Discussion}

Photosynthesis has long been recognized as one of the most heat-sensitive metabolic processes in plants (Zhang and Sharkey, 2009). It has also been reported that photosystems (mainly photosystem II with its oxygen-evolving system), ATP generation and carbon fixation reactions are three major heat-sensitive sites in the photosynthetic apparatus (Allakhverdiev et al., 2008). It has been proposed that heat stress alters the redox balance of photosynthetic electron transport reactions (Zhang and Sharkey, 2009). Therefore, in this study, chlorophyll a fluorescence measurement was used to investigate the performance of the photosynthetic apparatus in cucumber cotyledons under moderate and severe heat stress. The maximum quantum efficiency 
of PSII (as indicated by the $\mathrm{Fv} / \mathrm{Fm}$ ) in the cucumber cotyledons was not affected by moderate heat stress ( 45 ${ }^{\circ} \mathrm{C}$ ), but severe heat stress $\left(55^{\circ} \mathrm{C}\right.$ ) significantly reduced $\mathrm{Fv} / \mathrm{Fm}$ (Table 2). The lowest $\mathrm{Fv} / \mathrm{Fm}$ value in the severestressed cotyledons of cucumber plants clearly showed that a large extent of photoinhibition has occurred in PSII units. Similarly, moderate heat stress did not affect minimum fluorescence (Fo) and maximum fluorescence (Fm) significantly as compared to the respective controls (Table 2).

Table 2. Effect of moderate $\left(45^{\circ} \mathrm{C}\right)$ and severe heat stress $\left(55^{\circ} \mathrm{C}\right)$ on some chlorophyll a fluorescence parameter on cucumber cotyledons

\begin{tabular}{|c|c|c|c|}
\hline Parameters & Control & $45^{\circ} \mathbf{C}$ & $55^{\circ} \mathbf{C}$ \\
\hline Fo & $420 \pm 13 \mathbf{b}^{*}(100)^{* *}$ & $402 \pm 17 \mathbf{b}(96)$ & $585 \pm 50 \mathbf{a}(139)$ \\
\hline Fm & $2361 \pm 111 \mathbf{a}(100)$ & $2559 \pm 109 \mathbf{a}(108)$ & $787 \pm 89 \mathbf{b}(33)$ \\
\hline Fv/Fm & $0.821 \pm 0.005 \mathbf{a}(100)$ & $0.843 \pm 0.001 \mathbf{a}(103)$ & $0.259 \pm 0.05 \mathbf{b}(32)$ \\
\hline Fv/Fo & $3.39 \pm 0.13 \mathbf{b}(100)$ & $4.04 \pm 0.04 \mathbf{a}(119)$ & $0.33 \pm 0.07 \mathbf{c}(10)$ \\
\hline
\end{tabular}

${ }^{*}$ Different letters in the same lines indicate significant difference at the level of $\mathrm{P} \leq 0.05$.

** Numbers in the parenthesis indicate \% change from controls.

However, Fo was increased while Fm was decreased by severe heat stress remarkably in comparison with controls. It has been reported that several stress factors could be responsible for the increase in Fo (Maxwell and Johnson, 2000). Meravi and Prajapati (2018), for example, claimed that a higher level of Fo may be attributed to an increase in the fraction of PSII reaction centers that are in inactivated state. Kalaji et al. (2011) have shown that the reason for the higher Fo values is the slowing down of the transport of electrons from $Q_{A}$ to $\mathrm{Q}_{\mathrm{B}}$ and/or the decrease in the efficiency of PSII to capture light energy. Accordingly, the results of this study showed that severe heat stress resulted in damage to PSII reaction centers and decrease the quantum yield of electron transport $\left(\phi_{\mathrm{Eo}}\right)$ in the cotyledons of cucumber plants, as confirmed by higher ABS/RC and lower $\mathrm{RC} / \mathrm{ABS}$ values in this study (Table 3). The results of this study also suggest that the accumulation of inactive reaction centers is associated with the increased efficiency of dissipation of absorbed light energy as heat in the cotyledons of cucumber plants under severe heat stress, as shown by the remarkably higher values of those parameters indicating the efficiency of non-photochemical quenching processes (DIo/RC and $\phi_{D_{\mathrm{Do}}}$ ) (Table 3 ) (Kalaji et al., 2011). Also, severe heat stress led to the increased level of the accumulation of the closed reaction centers, as confirmed by higher $\Delta \mathrm{V} / \Delta$ to and lower $\mathrm{S}_{\mathrm{M}}$ and $\mathrm{TRo} / \mathrm{RC}$ values in the cotyledons of cucumber (Table 3).

Table 3. Effect of moderate $\left(45^{\circ} \mathrm{C}\right)$ and severe heat stress $\left(55^{\circ} \mathrm{C}\right)$ on some JIP test parameters on cucumber cotyledons

\begin{tabular}{|c|c|c|c|}
\hline Parameters & Control & $45^{\circ} \mathrm{C}$ & $55^{\circ} \mathrm{C}$ \\
\hline$\Delta \mathrm{V} / \Delta$ to & $1.14 \pm 0.07 \mathrm{ab}^{*}(100)$ & $0.93 \pm 0.03 \mathbf{b}(81)$ & $1.29 \pm 0.11 \mathrm{a}(112)$ \\
\hline$\phi \mathrm{Po}$ & $0.772 \pm 0.007 \mathbf{a}(100)$ & $0.801 \pm 0.001 \mathrm{a}(104)$ & $0.241 \pm 0.038 b(31)$ \\
\hline$\Psi_{0}$ & $0.476 \pm 0.021 \mathrm{a}(100)$ & $0.546 \pm 0.003 a(115)$ & $0.326 \pm 0.038 \mathbf{b}(69)$ \\
\hline$\phi \mathrm{Eo}_{0}$ & $0.368 \pm 0.019 b(100)$ & $0.437 \pm 0.003 a(119)$ & $0.084 \pm 0.021 c(23)$ \\
\hline$\phi D o$ & $0.228 \pm 0.007 \mathbf{b}(100)$ & $0.199 \pm 0.001 \mathrm{~b}(87)$ & $0.759 \pm 0.038 \mathrm{a}(333)$ \\
\hline$S_{M}$ & $19.81 \pm 1.61 \mathrm{ab}(100)$ & $24.08 \pm 0.37 \mathrm{a}(122)$ & $12.09 \pm 4.10 \mathrm{~b}(61)$ \\
\hline $\mathrm{N}$ & $42.81 \pm 2.85 \mathrm{a}(100)$ & $49.33 \pm 1.75 \mathrm{a}(115)$ & $22.32 \pm 7.09 \mathrm{~b}(52)$ \\
\hline $\mathrm{ABS} / \mathrm{RC}$ & $2.82 \pm 0.082 \mathrm{~b}(100)$ & $2.56 \pm 0.078 b(91)$ & $8.83 \pm 1.52 \mathrm{a}(313)$ \\
\hline TRo/RC & $2.18 \pm 0.047 \mathbf{a}(100)$ & $2.05 \pm 0.058 \mathrm{ab}(94)$ & $1.90 \pm 0.074 \mathrm{~b}(87)$ \\
\hline ETo/RC & $1.03 \pm 0.033 \mathrm{a}(100)$ & $1.12 \pm 0.030 \mathrm{a}(108)$ & $0.61 \pm 0.062 \mathbf{b}(59)$ \\
\hline $\mathrm{DIo} / \mathrm{RC}$ & $0.65 \pm 0.04 \mathrm{~b}(100)$ & $0.51 \pm 0.02 \mathbf{b}(79)$ & $6.93 \pm 1.51 \mathrm{a}(1074)$ \\
\hline$S F I_{A B S}$ & $1.31 \pm 0.098 \mathrm{~b}(100)$ & $1.72 \pm 0.056 \mathrm{a}(131)$ & $0.13 \pm 0.052 \mathrm{c}(10)$ \\
\hline $\mathrm{RC} / \mathrm{ABS}$ & $3.56 \pm 0.097 \mathrm{a}(100)$ & $3.93 \pm 0.110 \mathrm{a}(110)$ & $1.29 \pm 0.235 \mathrm{~b}(36)$ \\
\hline PI & $11.35 \pm 1.48 \mathrm{~b}(100)$ & $19.06 \pm 0.81 \mathrm{a}(168)$ & $0.30 \pm 0.15 \mathrm{c}(3)$ \\
\hline
\end{tabular}

${ }^{*}$ Different letters in the same lines indicate significant difference at the level of $\mathrm{P} \leq 0.05$.

${ }^{* *}$ Numbers in the parenthesis indicate \% change from controls. 
These results indicate that intact reaction centers cannot be easily oxidized as a result of severe heat stress. Consequently, electron movement into $Q_{A}$ is slowed down and the reduction/oxidation cycle of $Q_{A}$ is inhibited by severe heat stress, as shown by a lower level of $\mathrm{N}$ (Table 3). Under these circumstances, photosynthetic electron transport reactions further than QA are inhibited as well and hence both ETo/RC and $\Psi_{0}$ were decreased by severe heat stress. The lower level of $\mathrm{Fm}$ value in the cotyledons of cucumber plants, on the other hand, suggested that restrictive effect of severe heat stress on the photosynthetic electron transport reactions in PSII acceptor side appeared, as indicated by Georgieva and Lichtenthaler (1999) and Doğru and Çakırlar (2020a and b). Besides, the results of this study indicated that the decline in Fv/Fm ratio in the severe heat-stressed cotyledons of cucumber plants was mostly due to a decrease in Fm, suggesting a higher level of sensitivity of PSII acceptor side. The efficiency of the Hill reaction or water splitting complex on the donor side of PSII (as indicated by Fv/Fo) was enhanced in the cotyledons of cucumber under moderate heat stress, but it was significantly reduced by severe heat stress (Table 2). A higher level of Fv/Fo in the cotyledons of cucumber plants under moderate heat stress showed an accelerated rate of photosynthetic electron transport. In contrast, reduced $\mathrm{Fv} / \mathrm{Fo}$ value may be the assumption that a lower number of electrons were transported from the oxygen-evolving complex (OEC) to the plastoquinone pool, which could be a result of damages in OEC (Zhao et al., 2008). As a result of these changes in the photosynthetic electron transport, lower $\mathrm{PI}_{\mathrm{ABS}}$ and $\mathrm{SFI}_{\mathrm{ABS}}$ showed that structural damage and functioning failure occurred in PSII.

\section{Conclusions}

To sum up, the results of this study indicated that electron movements on PSII were entirely affected by heat stress applications in the cotyledons of cucumber plants. In general, severe heat stress had more destructive effects on photosynthetic electron transport reactions in cucumber plants in comparison with moderate heat stress. Severe heat stress led to the increased level of the accumulation of the inactive reaction centers and decreases the efficiency of PSII to capture light energy. Also, severe heat stress inhibited primary photochemistry and stimulated non-photochemical reactions. Consequently, the absorbed light energy could not be used to drive photochemical reactions and excess energy was quenched non-photochemically as heat.

\section{Authors' Contributions}

The author read and approved the final manuscript.

\section{Acknowledgements}

This work was supported by Sakarya University Scientific Research Projects Coordination Units (Grant number: 2015-50-01-048).

\section{Conflict of Interests}

The author declares that there are no conflicts of interest related to this article. 


\section{References}

Abdelrahman M, El-Sayed M, Jogaiah S, Burritt DJ, Tran LSP (2017). The "stay green" trait and phytohormone signaling networks in plants under heat stress. Plant Cell Reports 36:1009-1025. https://doi.org/10.1007/s00299-017$2119-y$

Allakhverdiev SI, Kreslavski VD, Kimov VV, Los DA, Carpentier R, Mohanty P (2008). Heat stress: an overview of molecular responses in photosynthesis. Photosynthesis Research 98:541. https://doi.org/10.1007/s11120-0089331-0

Biswal B, Joshi PN, Raval MK, Biswal U (2011). Photosynthesis, a global sensor of environmental stress in green plants: stress signaling and adaptation. Current Science 101:47-56. https://doi.org/10.2307/24077862

Chen ST, He NY, Chen JH, Guo FQ (2017). Identification of core subunits of photosystem II as action sites of HSP21, which is activated by the GUN5-mediated retrograde pathway in Arabidopsis. Plant Journal 89:1106-1118. https://doi.org/10.1111/tpj.13447

Doğru A (2019). Evaluation of lead tolerance in some barley genotypes by means of chlorophyll a fluorescence. Bartın University International Journal of Natural and Applied Science 2:228-238.

Doğru A, Çakırlar H (2020a). Effects of leaf age on chlorophyll fluorescence and antioxidant enzymes activity in winter rapeseed leaves under cold acclimation conditions. Brazilian Journal of Botany 43:11-20. https://doi.org/10.1007/s40415-020-00577-9

Doğru A, Çakırlar H (2020b). Is leaf age a predictor for cold tolerance in winter oilseed rape plants? Functional Plant Biology 47(3):250-262. https://doi.org/10.1071/FP19200

Force L, Critchley C, van Rensen JJS (2003). New fluorescence parameters for monitoring photosynthesis in plants. 1. The effect of illumination on the fluorescence parameters of the JIP test. Photosynthesis Research 78:17-33. https://doi.org/10.1023/A:1026012116709

Georgieva K, Lichtenthaler HL (1999). Photosynthetic activity and acclimation ability of pea plants to low and hightemperature treatment as studied by means of chlorophyll fluorescence. Journal of Plant Physiology 155:416423.

Govindjee (2004). Chlorophyll a fluorescence: a bit of basics and history. Springer, Dordrecht.

Kalaji MH, Govindjee, Bosa K, Koscielniak J, Golaszewska KZ (2011). Effects of salt stress on photosystem II efficiency and $\mathrm{CO}_{2}$ assimilation of two Syrian barley landraces. Environmental and Experimental Botany 73:64-72. https://doi.org/10.1016/J.ENVEXPBOT.2010.10.009

Maxwell K. Johnson NG (2000). Chlorophyll fluorescence-a practical guide. Journal of Experimental Botany 51:659-668. https://doi.org/10.1093/jexbot/51.345.659

Meravi N, Prajapati SK (2018). Temporal variation in chlorophyll fluorescence of different tree species. Biological Rhythm Research 49:1-7. https://doi.org/10.1080/09291016.2018.1528694

Schöffl F, Prandl R, Reindl A (1999). Molecular responses to heat stress. In: Shinozaki K, Yamaguchi-Shinozaki K (Eds). Molecular Responses to Cold, Drought, Heat and Salt Stress in Higher Plants, R.G. Landes Co., Austin, Texas, pp 81-99.

Sehgal A, Sita K, Nayyar H (2016). Heat stress in plants: Sensing and defense mechanism. Journal of Plant Science Research 32:195-210.

Strasser RJ, Srivastava A, Tsimilli-Michael M (2000). The fluorescence transient as a tool to characterize and screen photosynthetic samples. In: Yunus M, Pathre U, Mohanty P (Eds). Probing Photosynthesis: Mechanisms, Regulation and Adaptation. Taylor \& Francis, London, pp 445-483.

Wahid A, Gelani S, Ashraf M, Foola MR (2007). Heat tolerance in plants: an overview. Environmental and Experimental Botany 61:199-223. https://doi.org/10.1016/j.envexpbot.2007.05.011

Wang QL, Chen JH, He NY, Guo FQ (2018). Metabolic reprogramming in chloroplasts under heat stress in plants. International Journal of Molecular Science 19:849-870. https://doi.org/10.3390/ijms 19030849

Yusuf MA, Kumar D, Rajwanshi R, Strasser RJ, Tsimilli-Michael M, Govindjee, Sarin VB (2010). Overexpression of $\gamma$ tocopherol methyltransferase gene in transgenic Brassica juncea plants alleviates abiotic stress: physiological and chlorophyll fluorescence measurements. Biochimica et Biophysica Acta 1797:1428-1438. https://doi.org/10.1016/j.bbabio.2010.02.002

Zhang SR, Sharkey TD (2009). Photosynthetic electron transport and proton flux under moderate heat stress. Photosynthesis Research 100:29-43. https://doi.org/10.1007/s11120-009-9420-8 
Zhao B, Wang J, Gong H, Wen X, Ren H, Lu C (2008). Effects of heat stress on PSII photochemistry in cyanobacterium Spirulina platensis. Plant Science 175:556-564. https://doi.org/10.1016/j.plantsci.2008.06.003

OPEN ACCESS

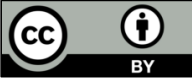

The journal offers free, immediate, and unrestricted access to peer-reviewed research and scholarly work. Users are allowed to read, download, copy, distribute, print, search, or link to the full texts of the articles, or use them for any other lawful purpose, without asking prior permission from the publisher or the author.

License - Articles published in Notulae Scientia Biologicae are Open-Access, distributed under the terms and conditions of the Creative Commons Attribution (CC BY 4.0) License.

(c) Articles by the authors; SHST, Cluj-Napoca, Romania. The journal allows the author(s) to hold the copyright/to retain publishing rights without restriction. 